\title{
Performances and Stall Delays of Three Dimensional Wind Turbine Blade Plate-Models with Helicopter-Like Propeller Blade Tips
}

\author{
Sutrisno $^{1}$, Deendarlianto ${ }^{1}$ Indarto $^{1}$, Sigit Iswahyudi ${ }^{1,3}$, M.A. Bramantya ${ }^{1}$ \& Setyawan B.W., \\ ${ }^{1}$ Department of Mechanical and Industrial Engineering, Faculty of Engineering, Gadjah Mada University, \\ Indonesia \\ ${ }^{2}$ Department of Mechanical Engineering, Vocation Program, Gadjah Mada University, Indonesia \\ ${ }^{3}$ Department of Mechanical Engineering, Tidar University, Magelang, Indonesia \\ Correspondence: Sutrisno, Department of Mechanical and Industrial Engineering, Faculty of Engineering, \\ Gadjah Mada University, Yogyakarta 55281, Indonesia. E-mail: mrsutrisnougm@gmail.com
}

Received: September 8, 2017

Accepted: September 18, 2017 Online Published: September 30, 2017

doi:10.5539/mas.v11n10p189

URL: https://doi.org/10.5539/mas.v11n10p189

The research is financed by the Department of Higher Education, the Republic of Indonesia.

\begin{abstract}
The research on three dimensional (3-D) wind turbine blades has been introduced (Sutrisno, Prajitno, Purnomo, \& B.W. Setyawan, 2016). In the current experiment, the 3-D wind turbine blades would be fitted with helicopter-like blade tips and additional fins to the blade hubs to demonstrate some laminarizing features.

It was found that additional helicopter-like blade tip to the turbine blade creates strong laminar flows over the surface of the blade tips. Supplementary, finned hub, fitted to the blade body, creates rolled-up vortex flows, weakens the blade stall growth development, especially for blades at high-speed wind. A proposed mathematical form of modified lifting line model has been developed to pursue further 3-d blade development study of 3-d wind turbine blade.

Rolled up vortex effects, developed by finned of the base hub, has been acknowledged could demolish the turbulent region, as well as laminarize the stall domain to intensify the induced wind turbine blade lift.
\end{abstract}

Keywords: flow visualization, 3-D wind turbine blades, finned hub, helicopter-like blade tip, stall delay propagation, lifting line theory

\section{Introduction}

Since the early research development of the wind turbine rotor theory, the wind turbine blade was divided into a number of independent spanwise sections and the induced velocities could be calculated. This method for infinitely many blades was called the blade element momentum (BEM) theory. The development continued with a derivation of the Kutta-Joukowsky theorem (Valery L Okulov, Sørensen, \& Wood, 2014).

Several researches simulating the 3-D blade stall propagation have been reported. For low-speed wind turbines, it has been identified that stall spreads from the root of the rotating blade (Dumitrescu \& Cardos, 2012; Dumitrescu \& Cardoş, 1989). A study on stall-delay for horizontal axis wind turbines (HAWT) (Hu, Hua, \& Du, 2006), and the energetic turbulence structures during stall delay has been elucidated (Wu, Mun, \& Tang, 2015). Consecutive modeling of inboard stall delay due to rotation has been performed, gave a conceptualization of the complex 3-D flow field on a rotor blade where stall begins and how it progresses (Dumitrescu \& Cardoş, 2002; Dumitrescu, Cardoş, \& Dumitrache, 2007). Computational fluid dynamic (CFD) investigations have been conducted at different wind speeds from $5 \mathrm{~m} / \mathrm{s}$ to $9 \mathrm{~m} / \mathrm{s}$ showing the flow characteristics and the stall delay phenomenon of wind turbine rotor due to blade rotation (Yu, Shen, Zhu, \& Du, 2011).

Sutrisno et al.(Sutrisno et al., 2016) initiated a research on the performance and the flow visualization of 3-D wind turbine blade models, acquainted as "UGM 3-D Blade". Here the blade shapes, generally straight following the BEM theory, were modified to become 3-dimensional by fastening the backward and forward blade parts to the base and the tip of the wind turbine blades. They found that the backward and forward curved sections of the blades affected the growths of the blade stall delay. The stall growth delay of the backward blade would 
decelerate the stall development so that as the wind pushing the blade faster, it would increase the blade to rotate quicker.

They conducted flow visualization also, using the tuft pattern, to envisage the flow. Several flow patterns were documented, laminar flows, weak stall flows, half stall flows, stall-to-tip and fully stall flow patterns. Several pattern combinations were also identified, weak stall with disturbed laminar (WSDL) pattern, weak stall disturbance with moderate transitional laminar (WSMTL), and strong stall to tip with wavy flow (SSTWF).

Several researches related with disturbances in aerodynamic models have been investigated. Ferreira, et al. have conducted the project for the validation of 2-D aerodynamic blade models with experimental data of an airfoil with unsteady flap (Ferreira et al., 2016). Full-scale wind turbine test of vortex generators mounted on the entire blade have been studied (Bak et al., 2016). The latest results from an aerodynamic modeling of $10 \mathrm{MW}$ wind turbines project have been investigated (Schepers, 2016).

\subsection{The Noise Characteristic, Generation and Its Propagation Models}

When the wind turbine blade planform changes, the noise response characteristics of the blade would change too. Essentially in most countries, the noise emanating from wind turbine systems become more sensitive disturbance issues.

It is known that noise sources are from i) the inflow or leading edge flow from the atmospheric turbulence, ii) the low-frequency disturbances radiating from the separation lines on blade surfaces, iii) the high-frequency noise originally from small vortices near the trailing edge, and iv) the stall noises from the spreading stall and tip disturbances radiated from the blade tips (Bertagnolio, Aagaard Madsen, Fischer, \& Bak, 2015). Some researches on the subject of noise characteristic, generation, prediction and propagation modeling have also been conducted (Barlas, Zhu, Shen, \& Andersen, 2016; Bertagnolio, 2016; Boorsma \& Schepers, 2011; Hansen, Zajamsek, \& Hansen, 2015; Lee et al., 2016; Mathew, Singh, Madsen, \& Arce León, 2016; Moller \& Pedersen, 2010; Smith, Bullmore, Cand, \& Davis, 2012; Søndergaard, 2014).

It is unfortunate that some scholars give limited attention to possibilities that the blades would change from a straight blade planform, to become 3-D blade planform which have backward and forward swepts. It is likely that, for 3-D planform, the characteristics of the above noise sources would alter. As the blade becomes swept rotating 3-D blades, the small vortices with high-frequency noise from the trailing edge and the large vortices with low frequency noise from the separation lines would change in their distribution and directivity. It is probable, as the shape of the wind turbine blade planform change, noise propagation and generation modeling would gradually change as well.

Some noise researches related with wind turbine noises have been done. The noise emission of a $200 \mathrm{~kW}$ vertical axis wind turbine has been investigated (Möllerström, Ottermo, Hylander, \& Bernhoff, 2015). The measurement of wind turbine coherent infrasound has been conducted (Vanderkooy \& Mann, 2014). Hansen et al. have investigated infrasound and low-frequency noise from wind turbines (Hansen et al., 2015).

\subsection{Output Control and Modified Design in wind Turbines}

As the wind turbine blade planform changes, the wind turbines control system characteristics would change too. There are 4 types of wind turbine control systems (Tahani, Rahbari, Memarian, \& Mirmahdian, 2011), i) stall control systems, ii) pitch control systems, iii) the active stall control systems, and iv) yaw control systems. When wind turbines are analyzed based on 3-D modeling, the system behaviors would probably alter also. Some researches in stall regulated wind turbines to output power controls have recently been conducted (Bourlis, 2011; Maheswari \& Tamilvendhan, 2012; Pereira, Bussel, \& Timmer, 2014). Pitch control and fixed pitch mechanisms have also been the subjects of investigations (Boorsma \& Schepers, 2016; Farouk \& Gawad, 2013; Leroy et al., 2016; Neammanee, Sirisumrannukul, \& Chatratana, 2010; Strom, Brunton, \& Polagye, 2016; Vijae, 2011). Modified design of wind turbines have also been investigated (Abdulhadi, 2012; Baldacchino et al., 2016; Elfarra, 2011; Lutz \& Wagner, 2000; Lynch, 2011; Maniaci et al., 2016; Perfilev, 2013; Rahimi, Hartvelt, Peinke, \& Schepers, 2016; Schubel \& Crossley, 2012).

Some other control and modified design of wind turbines have been carried out. A modeling and control of wind turbines have been conducted (Martinez, 2007). Bang et al. have made comparison between new active speed stall control and pitch control for a direct-drive wind turbine with different actuation methods (Bang \& Polinder, 2007). A conservative control strategy for variable-speed, stall-regulated wind turbines have also been investigated (Muljadi, Pierce, \& Migliore, 1998). 


\subsection{The Helicopter-Like Blade Tips and Triangular Fins}

In parallel with wind turbine blades study development, the researches in helicopter propeller blades have reached tremendous progresses. It has been concluded that 3 types of main rotor propeller blade tip designs have been identified (Brocklehurst \& Barakos, 2013). The 3 types are: i) the simple sheared-swept tip or swept-tapered-anhedral blade tip represents the propeller blade tip of the state of the art in the USA, while ii) the parabolic tip has been widely adopted in Europe, and iii) the BERP (British Experiment Research Program) tip remains a unique option in the UK.

On the other hands, it has been studied in the area of aeronautics, that a flow over a delta wing-like or a triangular fin surface has been characterized by a pair of counter-rotating leading-edge vortices that are formed by the rolled-up of vortex sheets (I. Ã. Gursul, Wang, \& Vardaki, 2007; I. Gursul, Gordnier, \& Visbal, 2005). As a result, additional vortex lift contributions are amplified with the increase of the delta wing-like sweep angle. With some important remark that rolled up vortices could produce powerful vortex center, contributing induced lift, when the swept of the triangular fin or delta wings is higher than 550 .

Lastly, in the design of wind turbine blades, when the main 3-D blade planform are fitted with both delta wing-like fin, in the formed of finned hubs, and helicopter-like propeller blade tips, one could expect that the whole system might experience performance improvement and noise suppressing enhancement suitable for large wind turbine blade designs, with diameter of $20 \mathrm{~m}$ and larger.

\subsection{The Extended Lifting Line Theory for 3-D Wind Turbine Blade Modeling}

The new 3-D wind turbine blade theory would bring about an alternative subject matter. It probably could create rolled-up vortices in the blade vortices system. The induced angle of attack of backward 3-D or delta planforms velocity fields would give curious thoughts of the modeling development employing the lifting line theory.

A new mathematical 3-D wind turbine blade model has to be constructed. In some wind turbine operating conditions, the rotor blades recurrently experience stall conditions. In order to accurately predict separated and stalled flows along the blade, coupling of the 2-D airfoil data, with an engineering approach has to be considered.

Kuchemann (Kuchemann, 1956) explained the lifting line theory for wing with various aspect ratio (AR), resulted from the Biot-Savart law. R.T. Jones applied shape parameters, to the theory such that the theory would be applicable more generally, especially for swept and elliptical wings. Lutz (2014) used extended lifting line theory, combined with the law of $1 / 4-3 / 4$ of Pistolesi, to model swept wings with finite AR. The solution of the integral equation was executed using Multhopp method, such that the quadratic formula was substituted to become a system of linear equations in M-dimensions. This system of equations was used to calculate spanwise lift coefficient along the wing. The vortex-lattice method could also be used to solve the equations.

In this research, in order to be applicable to wind turbine blades, rotational effects had to be introduced. The lifting line theory was utilized as lifting surface in special case for large aspect ratio (Ayati, 2010) which consisted of horse-shoe vortex distribution. First, one should calculate the induced velocity produced since the trailing vortex sheet aligned with the chord. Then the induced angle of attack was calculated, which would determine effective angle of attack. And the total circulation was computed, which would determine the lift based on Kutta condition. The lift calculation could be executed employing a) Fourier method or b) simplified method with different approaches. A vortex filament method for aerodynamic load calculations have been developed on rotor blades(Abedi, 2013).

Other similar researches have also been investigated. A propeller thrust analysis using the lifting line theory had been conducted, a comparison between the experimental thrust and the thrust predicted by the lifting line theory has been carried out (R. Kesler, 2014). Oliveira, et al. (de Oliveira, Pereira, Ragni, Avallone, \& van Bussel, 2016) had tried to explain how does the presence of a body affects the performance of an actuator disk.

An extension of Goldstein's circulation function for optimal rotors with hub had been solved (V L Okulov, Sørensen, \& Shen, 2016). A comparison of classical methods for blade design and the influence of tip correction on rotor performance had been conducted (Sørensen, Okulov, Mikkelsen, Naumov, \& Litvinov, 2016). The momentum theory of Joukowsky actuator discs with swirl had been worked out (Van Kuik, 2016) .

The purpose of this study is to investigate the performance of combination between the hub and the tip of 3-D wind turbine blade plate models with finned hub and helicopter-like propeller blade tips, introduced as "UGM 3-D blade type 2". The results would be confirmed using flow visualization techniques to analyze the flow patterns. 
For alternative tools to pursue further 3-D blade development study, a mathematical model of 3-D wind turbine blade using extended lifting line theory were developed. It employed 1/4-3/4 Pistolesi rule with rotation, and would be compared with the result of the actual experiment in the wind tunnel.

\section{Experimental Methods and Mathematical Model}

The main objective of this step is to perform torque, power output measurements and observe the flow visualization of the UGM 3-D blade type 2 in the wind tunnels to learn the characteristics of this particular blades.

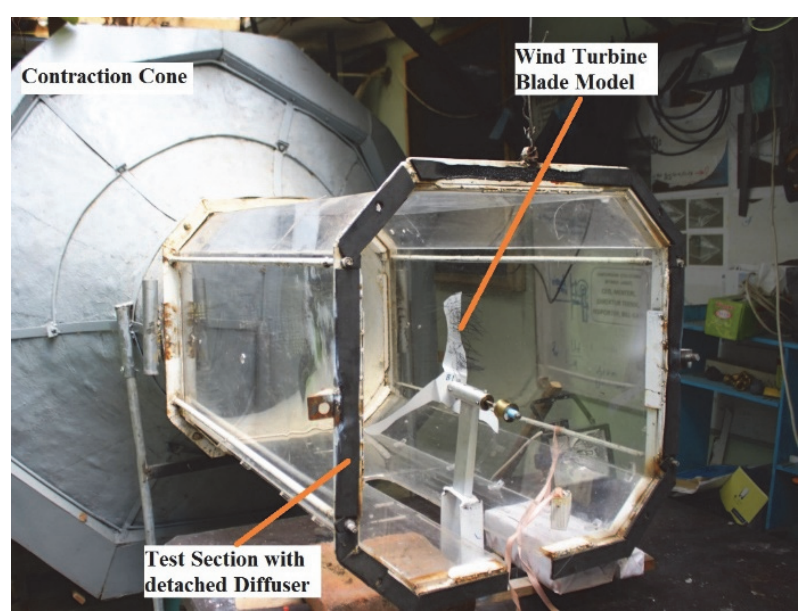

Figure 1. The torque meter installed in the wind tunnel, to measure the performance of the blades

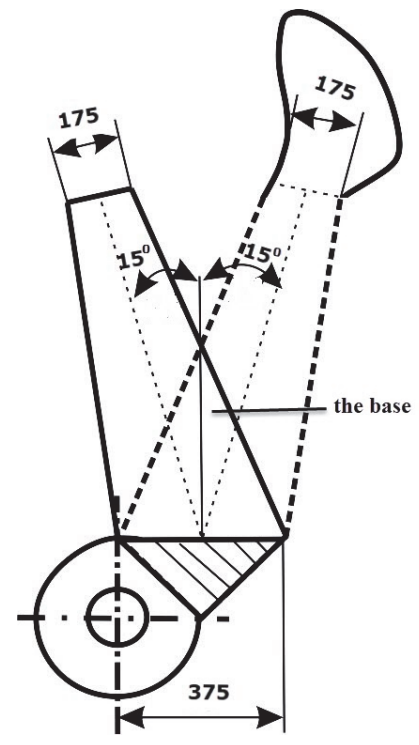

Figure 2. The galvanic blade plates have two types, the backward and forward blades, depending on the tilted of the blade plates which are bent $15^{0}$ to form backward and forward 3-D blade plate models. When the blade is bent, with an additional $46^{\circ}$ triangular plate, it will develop the twist of the blades

\subsection{Experimental Apparatus}

\subsubsection{The Wind Tunnel}

A $50 \mathrm{~cm} \times 50 \mathrm{~cm}$ wind tunnel, as illustrated in Fig. 1, were used to measure the rotating wind turbine blade model performance implementing a torque meter, utilizing Prony-type brake method. From the torque $(\mathrm{Q})$, rotation per minute (RPM) and wind speed (v), one could calculate the tip speed ratio (TSR), the output power (PT) and the coefficient of performance $(\mathrm{Cp})$ of the wind turbine blade plate models.

The "tuft" flow visualization technique has also been implemented employing the Nikon J3 camera to record the blade motion at 1200 frames/second. By analyzing the results of flow visualization one could learn the flow patterns around the blade which illustrate the dynamic of laminar flow and stall delay mechanism (Sutrisno et al., 
2016).

2.1.2 The 3-D wind turbine blade model design with helicopter-like blade tips and triangular fins (the UGM 3-D blade type 2)
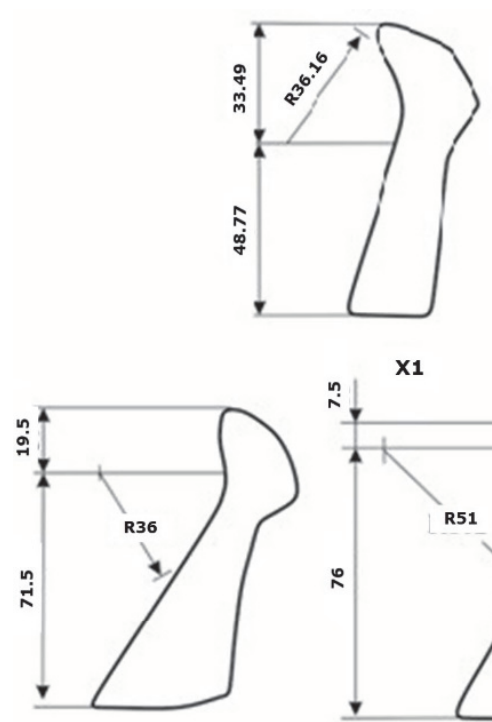

M4

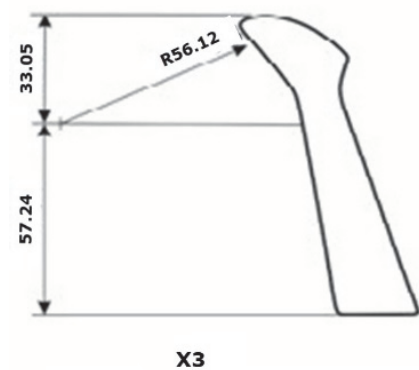

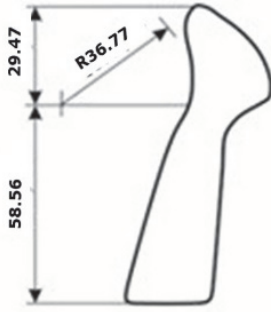

$\times 5$

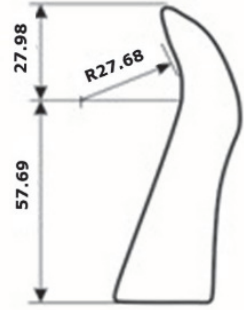

$\mathbf{X 2}$

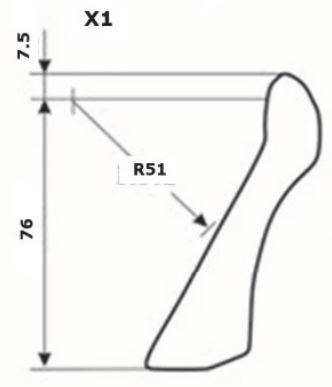

M3

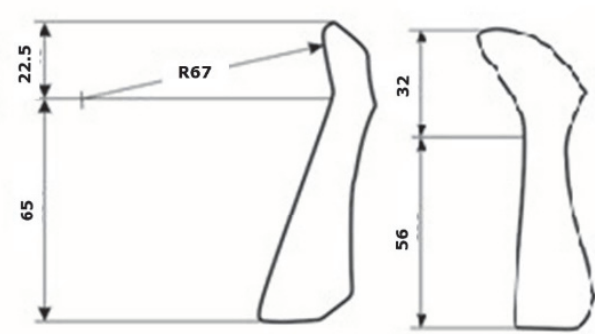

M2

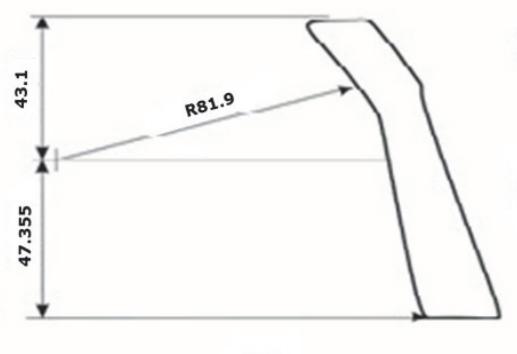

$\times 4$
B3

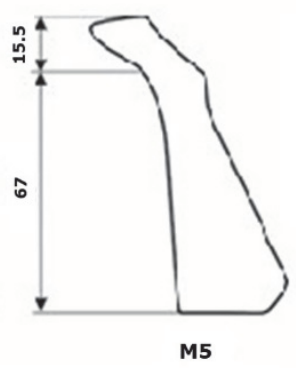

Figure 3. The schematic models of the backward X1, X5, X2, M4, M3, the straight, B3, and the forward X3, X4, M5, 3-D wind turbine blade plate-models with finned hubs and helicopter-like blade tips. The blade employ different helicopter blade tips a) BERP III, b) BERP IV, c) JpKd and d) SwTT

The backward turbine blade is originally a turbine blade with backward swept tip and forward swept root. For this study, due to the additional helicopter-like propeller blade head plate, the turbine backward swept tip element is removed, so that the turbine backward blades is the turbine blade with forward swept root element only, as sketched in Fig. 2. At the turbine blade tip, a helicopter-like propeller blade tip element is mounted, and when necessary the fin is fitted to the base of the hub. As it is shown in Fig. 2, when the blade plate model is bent $90^{\circ}$, with an additional $46^{\circ}$ triangular plate, it will develop the twist of the turbine blade curved-plate models.

There are 3 types of helicopter main propeller rotor blade tip designs have been identified (Brocklehurst \& Barakos, 2013), a) the simple sheared-swept tip or swept-tapered-anhedral tip that represents the state of the art in the USA, b) while in Europe the parabolic tip has been widely adopted, and c) in the UK, the BERP tip remains a unique preference.

In this study, due to their uniqueness designs, 4 popular types of helicopter-like propeller blade tips are chosen to be parts mounted on the head of backward and forward 3-D wind turbine blade models. That is a) BERP III, UK helicopter-like blade tip type, applied to the Puma helicopter b) BERP IV, UK type applied to the Super Puma helicopter, c) the Japan AT1 blade selected from several similar tip shapes (JpKd), which supersedes the Super Puma, d) Swept Tapered Tip (SwTT), a US helicopter-like blade tip type. The wind turbine blade designs employed in this experiment are shown in Fig. 3. The X blades are the blades with regular hubs and the M blades 
are the blades with finned hubs. The straight blade B3 is a classical wind turbine blade with the BERP III blade tip mounted on its head. It is chosen here as a reference classical 2-D blade to compare against the new designs.

\subsection{Experimental Procedures}

By applying the correlation between Cp versus the tip speed ratio (TSR) of the turbine, against the results of flow visualization technique, one could analyze the effectiveness of wind energy conversion into the generator electrical power, by learning the appearance of the laminar patterns, the patterns of weak stall, and half stalled flows surrounding the 3-D blade system to determine better qualifications for the turbine blade models.

In this experiment, the wind turbine blade plate models have to be drilled 2 to 4 rows spanwise, with $4 \mathrm{~mm}$ distance between holes. Regular sewing yarns have been used as tuft material, divided into three parts and inserted into the holes to form several tuft rows arranged in lines. The length of the tuft varies from $5 \mathrm{~cm}$ to $7 \mathrm{~cm}$ whenever necessary. As the air flows around the blades, the tuft rows would display airflow patterns surrounding the blade models.

\subsection{Mathematical Model of 3-D Blades Using Extended Lifting Line Theory}

\subsubsection{The Extended Lifting Line Theory for 3-D Wind Turbine Blades}

The extended lifting line theory, that is usually used to solve aerodynamics load problem in the swept wing, in the present paper are employed to analyze some wind turbine blade designs that had swept in their spans. Multhopp method is used to get lift coefficient by solving downwash integral equation. The method relates pressure difference across of a wing to downwash field of its surface using acceleration potential approach in conjunction with linearized Euler equations (Lamar, 1968). The method uses two control points i.e. one which gives lift with no pitching moment about $t / 4$ from leading each, where $t$ is the blade chord. And the other point that gives no lift but a pitching moment is about 3t/4 from leading each as shown in Fig. 4 (Lutz, 2014). A line that contains the first control points become bound vortex ( $\mathrm{t} / 4$-line of the wing planform) and a line that containing the second control points is as control line (Pistolesi-line). The relation between incidence angle and circulation according to extended lifting line theory as in Eq. (1).

$$
\alpha_{g}(y)=\frac{1}{4 \pi U_{\infty}} \lim _{\varepsilon \rightarrow 0}\left[\frac{4 \Gamma(y)}{\varepsilon}-\int_{-b / 2}^{y-\varepsilon} \frac{G\left(x_{P}, y ; y^{\prime}\right)}{\left(y-y^{\prime}\right)^{2}} d y^{\prime}-\int_{y+\varepsilon}^{b / 2} \frac{G\left(x_{P}, y ; y^{\prime}\right)}{\left(y-y^{\prime}\right)^{2}} d y^{\prime}\right]
$$

with the influence function

$$
G\left(x_{P}, y ; y^{\prime}\right)=\Gamma\left(y^{\prime}\right)\left(1+\frac{x_{P}-x^{\prime} g}{\sqrt{\left(x_{P}-x^{\prime} g\right)^{2}+\left(y-y^{\prime}\right)^{2}}}\right)
$$

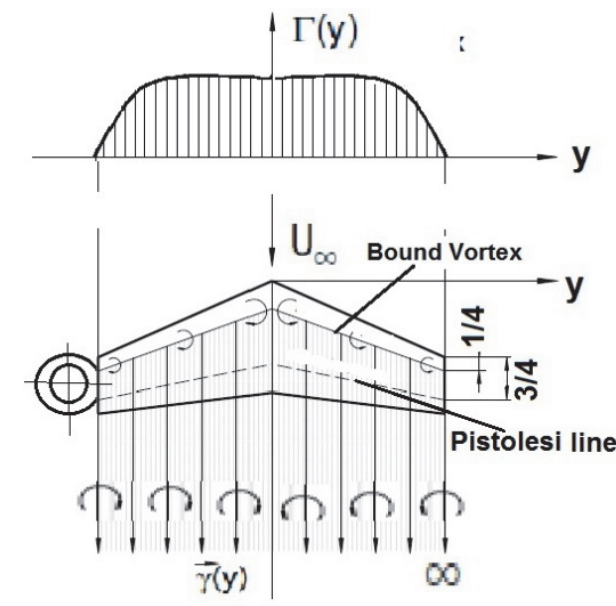

(a)

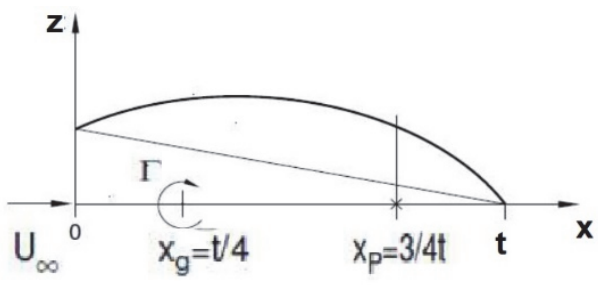

(b)

Figure 4. (a) Modeling the flow around a rotating wing refers to the theory of extended lifting line based on the Pistolesi principle, (b) cross-section of the airfoil flow modeling around wings extended in theory lifting-line. and normalized values: $\xi=2 x / d,: \eta=2 y / d$ and $\gamma(\eta)=\Gamma(\eta) /\left(d U_{\infty}\right)$. Then, equation for incidence angle in non-dimensional form can be written as in Eq. 3 


$$
\alpha_{g}(\eta)=\frac{1}{2 \pi} \int_{-1}^{1} K\left(\eta, \eta^{\prime}\right) \cdot \gamma\left(\eta^{\prime}\right) d \eta^{\prime}+\frac{1}{\pi} \int_{-1}^{1} \frac{d \gamma\left(\eta^{\prime}\right)}{d \eta^{\prime}} \frac{d \eta^{\prime}}{\eta-\eta^{\prime}}
$$

Pure geometrical influence factor is defined in Eq. 4.

$$
K\left(\eta, \eta^{\prime}\right)=\frac{1}{\left(\eta-\eta^{\prime}\right)^{2}}\left[1-\frac{\xi_{P}-\xi^{\prime} g}{\sqrt{\left(\xi_{P}-\xi^{\prime} g\right)^{2}+\left(\eta-\eta^{\prime}\right)^{2}}}\right]
$$

If $\eta^{\prime} \rightarrow \eta$, the factor becomes

$$
K(\eta, \eta)=\frac{1}{2\left(\xi_{P}-\xi_{g}\right)^{2}}
$$

In short form, Eq. 3 can be written as

\subsubsection{Rotational Effects}

$$
\alpha_{g}(\eta)=2\left[\tau(\eta)+\alpha_{i}(\eta)\right]
$$

In this section, the rotational effect will be included in extended lifting line theory to solve aerodynamics loads of some wind turbine blade designs. Wind turbine rotor rotates at a constant angular velocity $\Omega$, so that the blade has a getting greater tangential velocity, start from the base area (tangential velocity $=0$ at $y=-b / 2$ ) to the tip area (tangential velocity $=\Omega \mathrm{b}$ for $\mathrm{y}=b / 2$ (Ayati, 2010). A cross-sectional area on distance $d=\mathrm{y}+\mathrm{b} / 2$ from the hub, will have a tangential velocity $V t=(\mathrm{y}+b / 2) \Omega$. This cross-section will experience a wind blow in the opposite direction of the wind lift, on the negative $\mathrm{z}$ direction, as if there was an additional inflow in the vertical direction $V=-(\mathrm{y}+b / 2) \Omega$. This inflow components also influence the angle of attack.

$$
\alpha_{\text {rot }}(z)=-\tan ^{-1} \frac{\Omega(y+b / 2)}{U_{\infty}}
$$

Both the new inflow component and the induced angle of attack are obviously dependent on the spanwise location of the cross-section. Actually, it is due to the z-dependency in $\operatorname{\alpha rot}(\mathrm{z})$ that modern wind turbine blades have a twisted shape

The effect of rotation should be taken into account by finding the effective inflow velocity

$$
U_{e f f}(z)=\sqrt{U_{\infty}^{2}+(\Omega(y+b / 2))^{2}}
$$

and the effective angle of attack

$$
\alpha(y)=\alpha_{p i t c h}-\tan ^{-1} \frac{\Omega(y+b / 2)}{U_{\infty}}
$$

With the involvement of the new induced angle $\left(\tan ^{-1} \frac{\Omega y}{U}\right)$ which has been normalized to become $\tan ^{-1} \frac{\Omega b}{2 \eta U}$, and then, $\alpha(y)$ in Eq. (9) can be written in normalized form as $\alpha_{p i t c h}-\tan ^{-1} \frac{\Omega b}{2 \eta U_{\infty}}$. By inserting this term into the left hand side of Eq. (6), one could find equation for swept wing under rotation as follows.

$$
\alpha_{\text {pitch }}-\tan ^{-1} \frac{\Omega b}{2 \eta U_{\infty}}=2\left[\tau(\eta)+\alpha_{i}(\eta)\right]
$$

By inserting $b=\frac{2 \lambda \mathrm{U}}{\Omega}$ in to second terms of the left hand side of Eq. 10, the equation can be written as

$$
\alpha_{p i t c h}-\tan ^{-1} \eta \lambda=2\left[\tau(\eta)+\alpha_{i}(\eta)\right]
$$

If $\alpha_{g r}=\alpha_{\text {pitch }}-\tan ^{-1} \eta \lambda$, in short form, Eq. 11 can be written as follow

$$
\alpha_{g r}(\eta)=2\left[\tau(\eta)+\alpha_{i}(\eta)\right]
$$

Equation (12) has a similar form with equation (6) therefore the completion of the integral equation would also go through the same steps. Detail steps of integral equation solution can be seen in Lutz (2014) (Lutz, 2014). The 
lift coefficient and drag coefficient distribution along the span are solved as follows.

$$
\begin{gathered}
c_{a}\left(\vartheta_{\mu}\right)=\frac{2 b \cdot \gamma\left(\vartheta_{\mu}\right)}{t\left(\vartheta_{\mu}\right)} \\
c_{A}=\frac{\Lambda \pi}{M+1} \sum_{\mu}^{M} \gamma_{\mu} \sin \left(\vartheta_{\mu}\right)
\end{gathered}
$$

In this case, the drag coefficient $c_{d}$, is approached by Eq. 15 .

$$
c_{d}(\eta)=c_{a}(\eta) \alpha(\eta)
$$

The generated torsion $\mathrm{Q}$ is calculated by following equations.

$$
d Q=\frac{1}{2} \rho U_{e f f}^{2} c N C_{a} y d y
$$

Where, $\rho$ : air density, $U_{\text {eff }}$ : velocity of relative wind, $c$ : length of chord, $N$ : blade number and $C_{a \prime}=$ $c_{a} \sin \phi-c_{d} \cos \phi . \phi$ is angle between relative wind speeds with rotor plane. This angle is the sum of angle of attack and pitch angle. Power coefficient $\left(C_{p}\right)$ is solved by dividing produced power $(P)$ by power of the wind as in Eq. (18).

$$
\begin{gathered}
d P=\Omega d Q \\
C_{p}=\frac{P}{\frac{1}{2} \rho U_{\infty}^{3} A}
\end{gathered}
$$

\section{Results}

\subsection{Results from 3-D Wind Turbine Blade Mathematical Model using Lifting Line Theory with Rotation}

The formulation of mathematical model for 3-D wind turbine blade implementing a modified extended lifting-line theory employing 1/4-3/4 Pistolesi rule (Lutz, 2014) enriched with rotation (Ayati, 2010) has been constructed. The model could calculate the circulation vortex distribution, the induced velocity angle, the induced lift and induced drag distribution, the torque and power distribution. And the variation of the power coefficient with respect to the tip speed ratio could be presented.

In the development of the 3-D wind turbine blade mathematical model, it was assumed that the wind turbine blade plate equipped with helicopter-like propeller head and finned hub. For blades X5 and M3, the variation of the power coefficient, $\mathrm{Cp}$, as defined by (18), with respect to the tip speed ratio (TSR) could be evaluated, as presented in Fig. 5a and $\mathrm{b}$ for ambient velocity, $\mathrm{V}=3.4,3.8,4.1$ and $4.6 \mathrm{~m} / \mathrm{s}$.

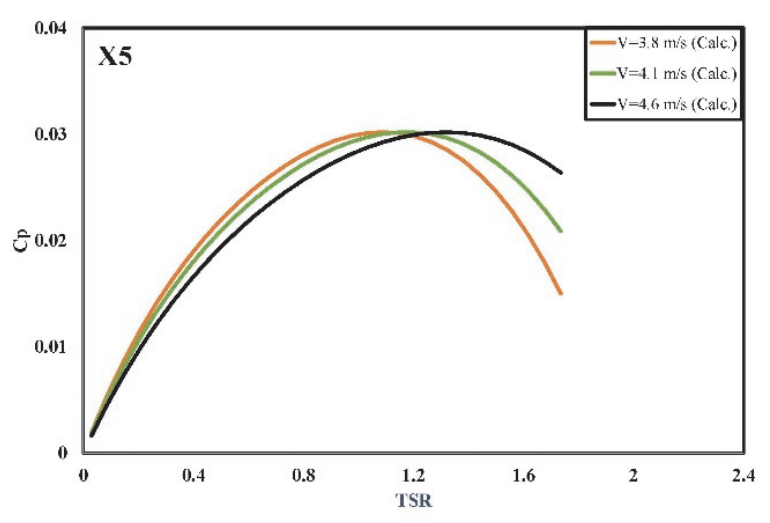

(a)

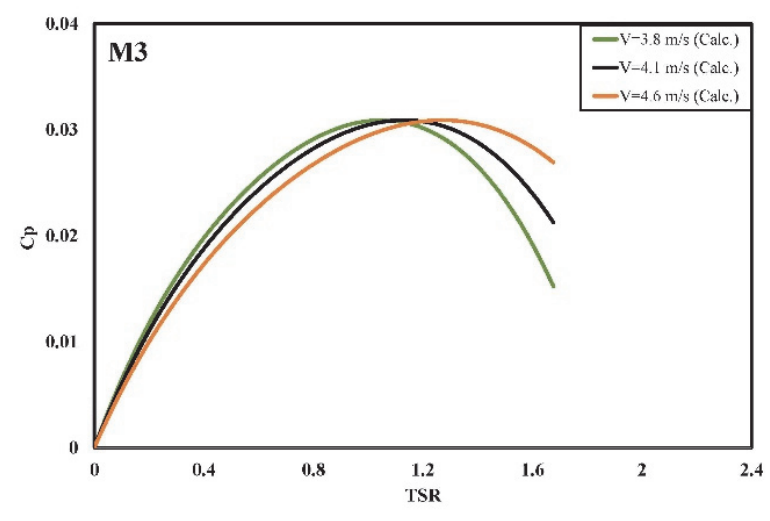

(b)

Figure 5. The power coefficient, $\mathrm{Cp}$, as a function of tip speed ratio (TSR) for a) blade X5 and b) blade M3 for V $=3.8,4.1$ and $4.6 \mathrm{~m} / \mathrm{s}$ calculated based on the lifting line theory following the Pistolesi principle 


\subsection{Performance Measurements of 3-D Turbine Blade Plate Models with Helicopter-Like Propeller Blade Heads and Finned Hubs}

From the torque measurements of the wind turbine blade models in the wind tunnel, the model performances $\mathrm{Cp}$ and correlated tip speed ratios are presented on Table 1-2. The blades are backward (BW) and forward (FW), either with regular hub (HR) or finned hub (HF) and, depending on the choice of helicopter-like blade tip, the tip is mounted with BERP IV or BERP III or SwTT when using swept taper tip, or JpKd when using the Japan AT1 blade tips.

The blades X1, X5, X2, X3, and X4 are turbine blades with regular hubs, while M4, M3 and M5 are turbine blades with finned hubs. One should note that the blade B3 is a straight blade with a finned hub and a BERP III blade tip, and the blade M5, is a forward blade with a finned hub and a Japan AT1 blade tip.

The performance for the blade M3 and X5 are presented on Fig. 6 and 7, where there are shown also the comparison between $\mathrm{Cp}$ versus TSR predicted, implementing "Lifting line theory" based on the Pistolesi principle with rotation, versus the actual measurement results.

Table 1. Wind turbine power coefficient, $\mathrm{Cp}$ versus tip speed ratio (TSR) for blades with regular hub (HR)

\begin{tabular}{llllllll}
\hline $\begin{array}{l}\text { Blade } \\
\text { Name }\end{array}$ & $\begin{array}{l}\text { Regular/ } \\
\text { Finned } \\
\text { Hub }\end{array}$ & $\begin{array}{l}\text { Tilt Angle } \\
\text { (degrees) }\end{array}$ & $\begin{array}{l}\text { Backward or } \\
\text { Forward }\end{array}$ & $\begin{array}{l}\text { Helicopter-like } \\
\text { Blade Tip }\end{array}$ & $\begin{array}{l}\text { Optimal } \\
\text { Wind } \\
\text { Velocity } \\
(\mathrm{m} / \mathrm{s})\end{array}$ & $\begin{array}{l}\text { Power } \\
\text { Coefficient } \\
(\mathrm{Cp})\end{array}$ & $\begin{array}{l}\text { Tip } \\
\text { Speed } \\
\text { Ratio }\end{array}$ \\
\hline X1 & HR & 15 & BW & BERP IV & 4.1 & 0.071 & 1.8 \\
X5 & HR & 15 & BW & BERP III & 4.6 & 0.030 & 1.9 \\
X2 & HR & 15 & BW & JpKd & 4.6 & 0.029 & 2.1 \\
X3 & HR & 15 & FW & BERP III & 4.1 & 0.026 & 1.8 \\
X4 & HR & 15 & FW & SwTT & 3.8 & 0.025 & 1.6 \\
\hline
\end{tabular}

Table 2. Wind turbine power coefficient Cp versus tip speed ratio (TSR) for blades with finned hub (HF)

\begin{tabular}{cccccccc}
\hline Blade & $\begin{array}{c}\text { Regular/ } \\
\text { Finned } \\
\text { Hume }\end{array}$ & $\begin{array}{c}\text { Tilt } \\
\text { Angle } \\
\text { (degrees }\end{array}$ & $\begin{array}{c}\text { Backward or } \\
\text { Forward }\end{array}$ & $\begin{array}{c}\text { Helicopter-lik } \\
\text { e Blade Tip }\end{array}$ & $\begin{array}{c}\text { Optimal } \\
\text { Wind } \\
\text { Velocity } \\
(\mathrm{m} / \mathrm{s})\end{array}$ & $\begin{array}{c}\text { Power } \\
\text { Coefficient } \\
\text { (Cp) }\end{array}$ & $\begin{array}{c}\text { Tip } \\
\text { Speed } \\
\text { Ratio }\end{array}$ \\
\hline M4 & HF & 15 & BW & BERP IV & 4.1 & 0.051 & 1.6 \\
M3 & HF & 15 & BW & BERP III & 4.1 & 0.031 & 1.9 \\
B3 & HF & 0 & STRAIGHT & BERP III & 4.1 & 0.021 & 1.8 \\
M5 & HF & 15 & FW & JpKd & 4.6 & 0.027 & 1.7 \\
\hline
\end{tabular}

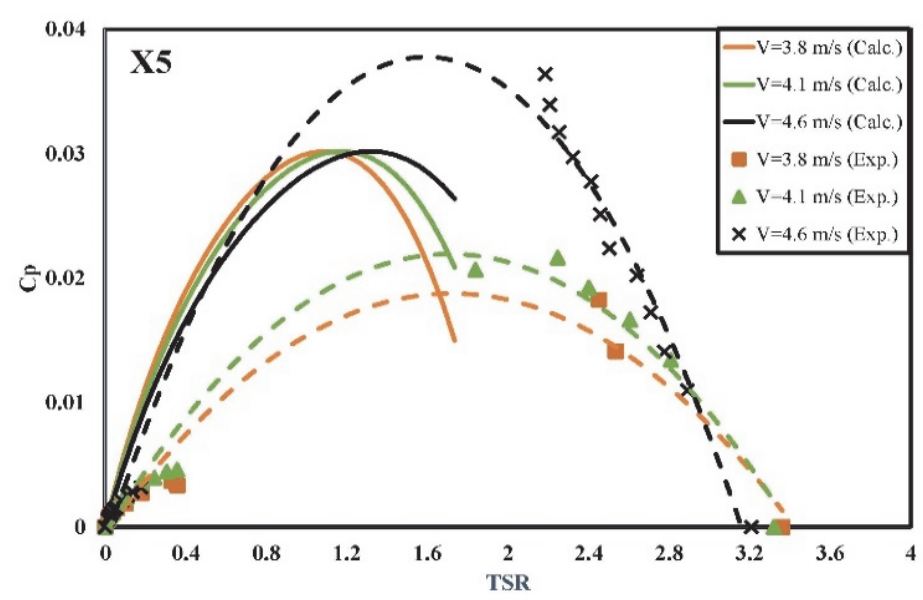

Figure 6. The graph of power coefficient Cp versus Tip Speed Ratio of backward blade X5 with regular hub and BERP III helicopter-like blade tip with maximum $\mathrm{Cp}=0.071$ at $\mathrm{v}=4.1 \mathrm{~m} / \mathrm{s}$ and $\mathrm{RPM}=450$ compared with that calculated based on the lifting line theory following the Pistolesi principle 


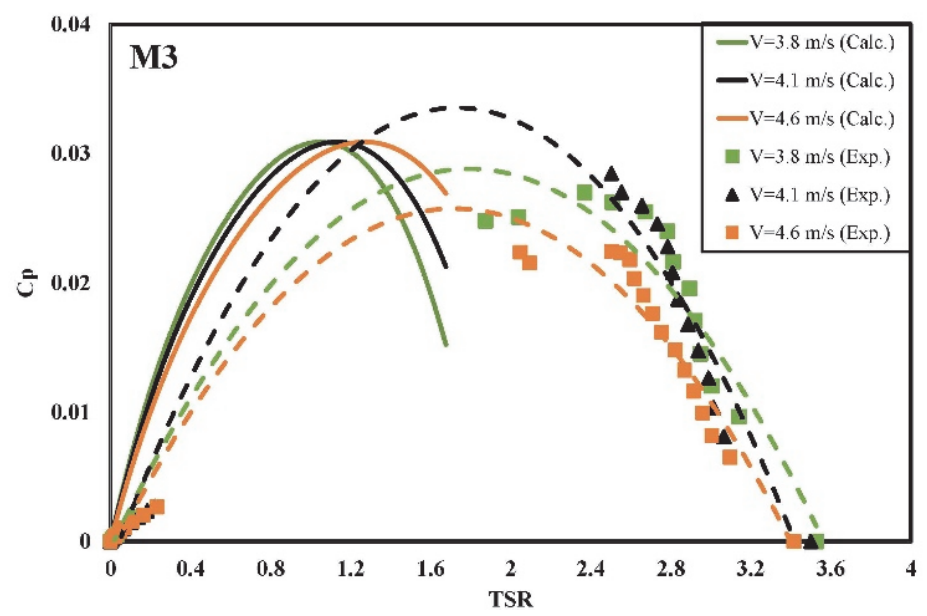

Figure 7. Power coefficient Cp versus Tip Speed Ratio of backward blade M3 with finned hub and BERP III helicopter-like propeller blade tip with maximum $\mathrm{Cp}=0.031$ at $\mathrm{v}=4.1 \mathrm{~m} / \mathrm{s}$ and $\mathrm{RPM}=490$ compared with that calculated based on the lifting line theory following the Pistolesi principle

\subsection{Flow Visualizations of 3-D Wind Turbine Blade Models Fitted with Finned Hubs and Helicopter-Like Propeller Blade Tips}

It is known that backward blades give better performance than forward blades. For the backward blades, with forward swept root, the initial stall at the blade bottom would be weakened by opposite weakening flow due to the forward swept root, generates weak stall that tends to deteriorate. An increase of wind turbine blades performances was attained by variety effort of additional helicopter-like propeller blade tips and finned hubs on the backward and forward turbine blades.

Flow visualization results of blades X5, M4, B3, X3 and M5 are presented in Fig. 8 to 12 showing the blade name, type of the blade tip swept, blade RPM, tip speed ratio, stall propagation patterns due to the blade tip and finned hub, degree of turbulence and stall types or flow characteristics.

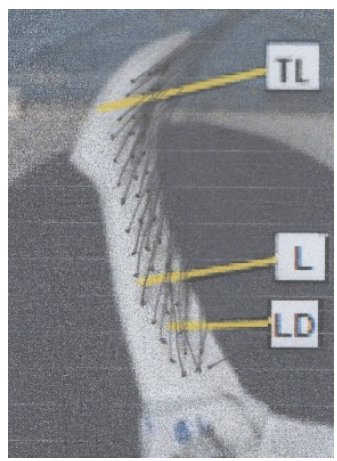

a) Laminar

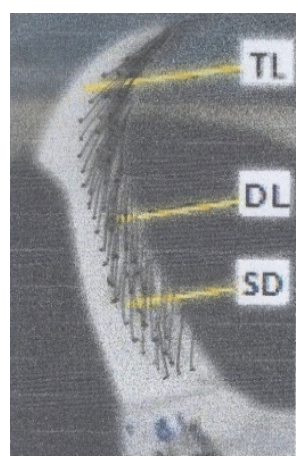

b) Disturbed Laminar

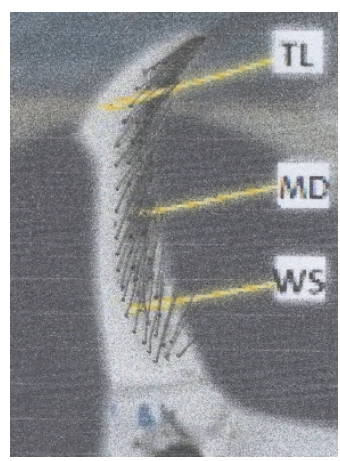

c) Weak Stall

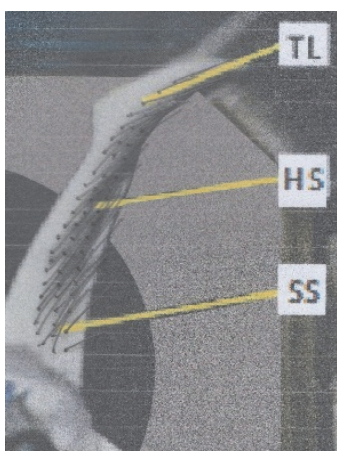

d) Half Stall

Figure 8. Flow visualization for backward blade X5 with regular hub and BERP III helicopter-like propeller blade tip showing a) laminar flow at $\mathrm{v}=3.4 \mathrm{~m} / \mathrm{s}$ and $\mathrm{RPM}=286 \mathrm{~b}$ ) disturbed laminar flow at $\mathrm{v}=3.8 \mathrm{~m} / \mathrm{s}$ and $R P M=308 \mathrm{c}$ ) weak stall flow at $\mathrm{v}=4.1 \mathrm{~m} / \mathrm{s}$ and $\mathrm{RPM}=345$ and d) half stall flow at $\mathrm{v}=4.6 \mathrm{~m} / \mathrm{s}$ and $\mathrm{RPM}=405$. Here, $\mathrm{TL}=$ strong tip laminar flow, $\mathrm{L}=$ laminar, $\mathrm{LD}=$ with little disturbance, $\mathrm{DL}=$ disturbed laminar, $\mathrm{SD}=$ stall disturbance, $\mathrm{MD}=$ middle disturbance, $\mathrm{WS}=$ weak stall, $\mathrm{HS}=$ half stall and $\mathrm{SS}=$ strong stall disturbance 


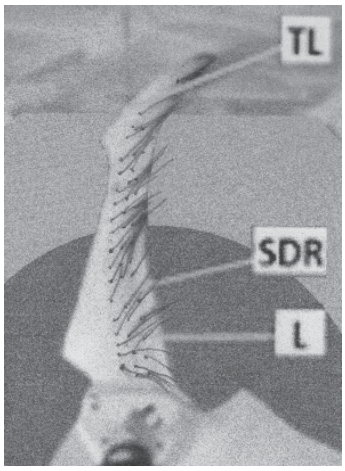

Laminar

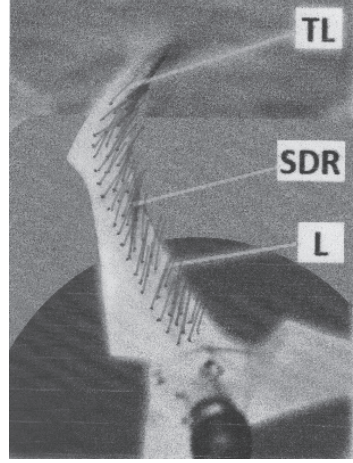

Laminar

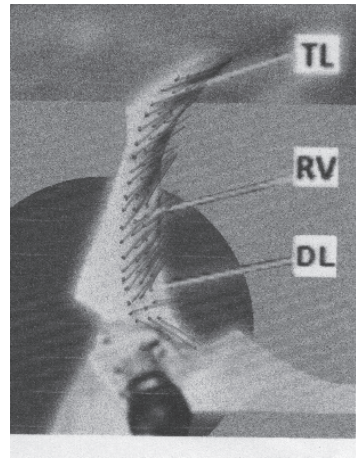

Disturbed Laminar

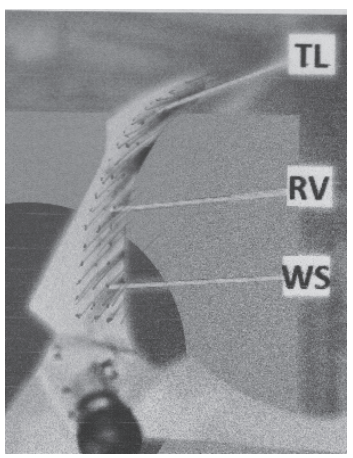

Weak Stall

Figure 9. Flow visualization for backward blade M4 with finned hub and BERP IV helicopter-like blade tip showing a) laminar flow at $\mathrm{v}=3.4 \mathrm{~m} / \mathrm{s}$ and $\mathrm{RPM}=262 \mathrm{~b}$ ) laminar flow at $\mathrm{v}=3.8 \mathrm{~m} / \mathrm{s}$ and $\mathrm{RPM}=296 \mathrm{c}$ ) disturbed laminar flow at $\mathrm{v}=4.1 \mathrm{~m} / \mathrm{s}$ and $\mathrm{RPM}=302$ and $\mathrm{d}$ ) weak stall flow at $\mathrm{v}=4.6 \mathrm{~m} / \mathrm{s}$ and $\mathrm{RPM}=314$.

Rolled-up vortex effects are clearly visible. Here, $\mathrm{TL}=$ strong tip laminar flow, $\mathrm{SDR}=$ some disturbed region, $\mathrm{L}=$ laminar, $\mathrm{RV}=$ rolled-up vortex effect, $\mathrm{DL}=$ disturbed laminar, $\mathrm{WS}=$ weak stall

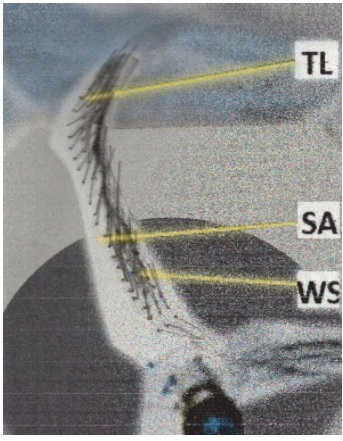

Weak Stall

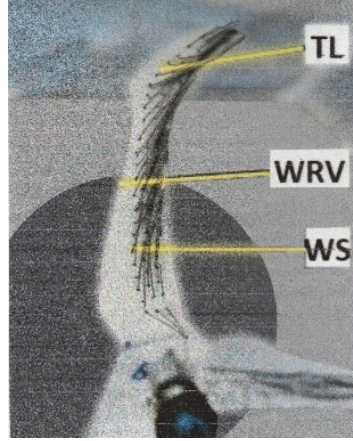

Weak Stall

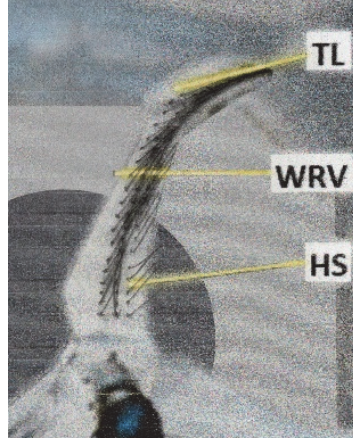

Half Stall

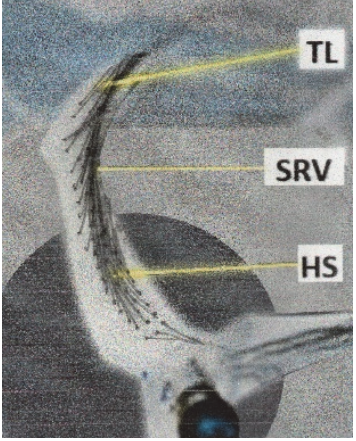

Half Stall

Figure 10. Flow visualization for straight blade B3 with finned hub and BERP III helicopter-like propeller blade tip showing a) weak stall flow at $\mathrm{v}=3.4 \mathrm{~m} / \mathrm{s}$ and $\mathrm{RPM}=213 \mathrm{~b}$ ) weak stall flow at $\mathrm{v}=3.8 \mathrm{~m} / \mathrm{s}$ and $\mathrm{RPM}=254 \mathrm{c}$ ) half stall flow at $\mathrm{v}=4.1 \mathrm{~m} / \mathrm{s}$ and $\mathrm{RPM}=294$ and $\mathrm{d}$ ) half stall flow at $\mathrm{v}=4.6 \mathrm{~m} / \mathrm{s}$ and $\mathrm{RPM}=360$. Rolled-up vortex effects are still visible. Here, $\mathrm{TL}=$ tip laminar, $\mathrm{SA}=$ strongly accelerated, $\mathrm{WS}=$ weak stall, $\mathrm{WRV}=\mathrm{weak}$ rolled-up vortex and $\mathrm{SRV}=$ strong rolled-up vortex, $\mathrm{HS}=$ half stall

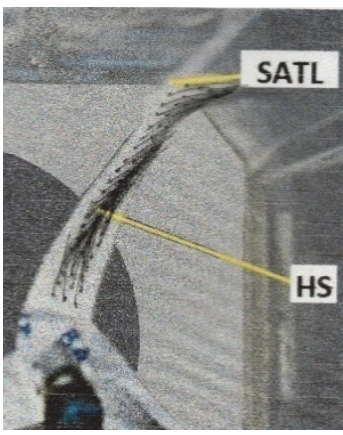

Half Stall

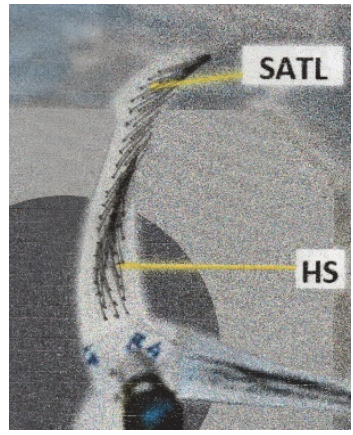

Half Stall

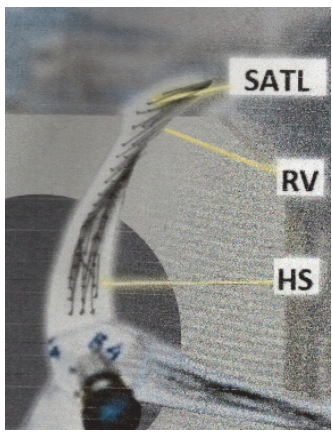

Half Stall

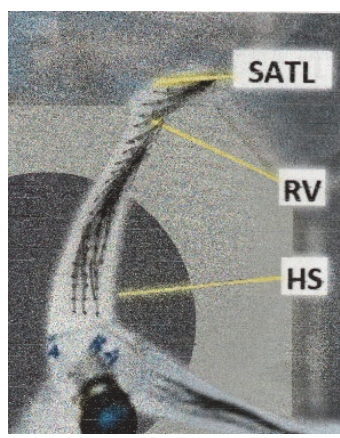

Half Stall

Figure 11. Flow visualization for forward blade X3 with regular hub and BERP III helicopter-like propeller blade tip showing a) half stall flow at $v=3.4 \mathrm{~m} / \mathrm{s}$ and $\mathrm{RPM}=282 \mathrm{~b}$ ) half stall flow at $\mathrm{v}=3.8 \mathrm{~m} / \mathrm{s}$ and $\mathrm{RPM}=338 \mathrm{c}$ ) half stall flow at $\mathrm{v}=4.1 \mathrm{~m} / \mathrm{s}$ and $\mathrm{RPM}=402$ and $\mathrm{d}$ ) half stall flow at $\mathrm{v}=4.6 \mathrm{~m} / \mathrm{s}$ and $\mathrm{RPM}=412$. Here, $\mathrm{SATL}=$ strongly affected tip laminar flow, $\mathrm{RV}=$ rolled-up vortex and $\mathrm{HS}=$ half stall 


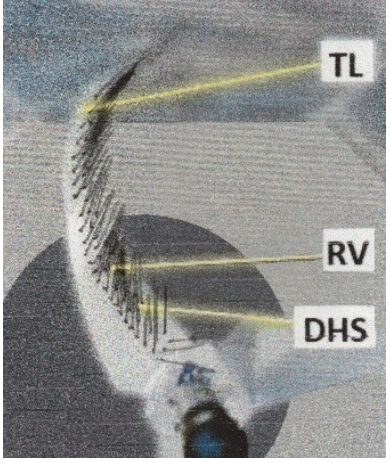

Disturbed Half Stall

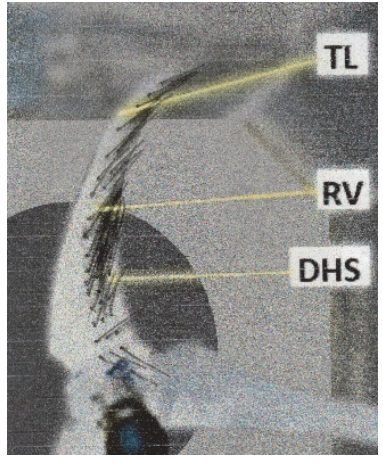

Disturbed Half Stall

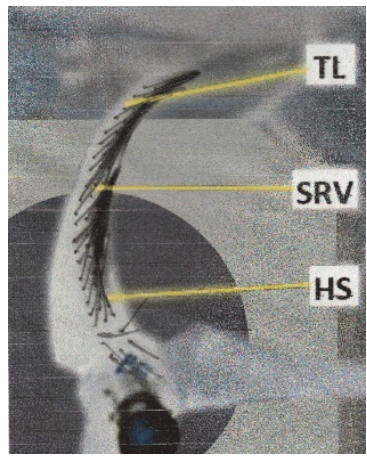

Half Stall

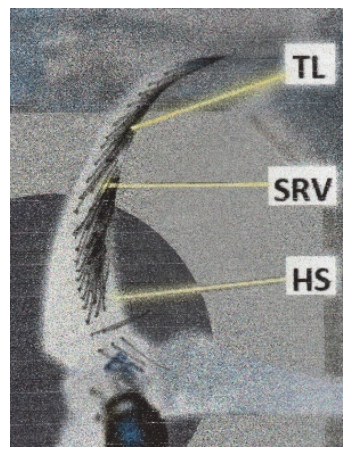

Half Stall

Figure 12. Flow visualization for forward blade M5 with finned hub and JpKd helicopter-like propeller blade tip showing a) disturbed half stall flow at $\mathrm{v}=3.4 \mathrm{~m} / \mathrm{s}$ and $\mathrm{RPM}=294 \mathrm{~b}$ ) disturbed half stall flow at $\mathrm{v}=3.8 \mathrm{~m} / \mathrm{s}$ and $R P M=326 \mathrm{c}$ ) half stall flow at $\mathrm{v}=4.1 \mathrm{~m} / \mathrm{s}$ and $\mathrm{RPM}=364$ and d) half stall flow at $\mathrm{v}=4.6 \mathrm{~m} / \mathrm{s}$ and $\mathrm{RPM}=410$. Rolled-up vortex effects are clearly visible. Here, $\mathrm{TL}=$ tip laminar flow, $\mathrm{RV}=$ rolled-up vortex, $\mathrm{DHS}=$ disturbed half stall, $\mathrm{SRV}=$ strong rolled-up vortex and $\mathrm{HS}=$ half stall

\section{Discussion}

\subsection{Flow Visualization Experiment Results}

In Fig. 8 to 12, the flow visualization of the backward blades X5 and M4, the forward blades X3, M5, and a straight blade B3 with finned hub and BERP III blade tip are presented. One should underline that helicopter-like propeller blade tips, BERP IV, BERP III, SwTT and JpKd, create strong laminar flows over the surface of the blade tips.

Table 3. Flow visualization mapping of flow surrounding backward \& forward 3-D wind turbine blade with finned hub \& helicopter-type blade tip plate-models

\begin{tabular}{|c|c|c|c|c|c|c|c|c|}
\hline $\begin{array}{l}\text { Figure } \\
\text { no. }\end{array}$ & $\begin{array}{l}\text { Blade } \\
\text { name }\end{array}$ & $\begin{array}{l}\text { Wind } \\
\text { velocit } \\
y(\mathrm{~m} / \mathrm{s})\end{array}$ & $\begin{array}{l}\text { Type of } \\
\text { blade } \\
\text { swept }\end{array}$ & $\begin{array}{l}\text { f Blade } \\
\text { RPM }\end{array}$ & $\begin{array}{l}\text { Reynolds } \\
\text { number: } \\
\operatorname{Re}^{*} 10^{-3}\end{array}$ & $\begin{array}{l}\text { Stall propagation } \\
\text { pattern due to blade } \\
\text { tip and finned hub }\end{array}$ & $\begin{array}{l}\text { Degree of } \\
\text { turbulence }\end{array}$ & $\begin{array}{l}\text { Stall type/ } \\
\text { flow } \\
\text { characteristic }\end{array}$ \\
\hline & & & & & & Backward blades & & \\
\hline Fig $8 \mathrm{a}$ & $\mathrm{X} 5$ & 3.4 & backward & 286 & 2.078 & "'” LWLD & weak & Laminar \\
\hline Fig $8 b$ & $\mathrm{X} 5$ & 3.8 & backward & 308 & 2.078 & $\stackrel{\text { "' }}{\equiv}$ & weak & $\begin{array}{l}\text { Disturbed } \\
\text { laminar }\end{array}$ \\
\hline Fig $8 \mathrm{c}$ & $\mathrm{X} 5$ & 4.1 & backward & 345 & 2.494 & "'”』 WSLD & weak & Weak stall \\
\hline Fig $8 d$ & $\mathrm{X} 5$ & 4.6 & backward & 405 & 2.494 & "'” & strong & Half stall \\
\hline Fig 9a & M4 & 3.4 & backward & 262 & 2.910 & $\stackrel{\text { Iv }}{=} \|_{\text {LSDR }}$ & weak & Laminar \\
\hline Fig $9 b$ & M4 & 3.8 & backward & 296 & 2.910 & $\stackrel{\text { ve }}{\equiv}={ }_{\text {LSDR }}$ & weak & Laminar \\
\hline Fig 9c & M4 & 4.1 & backward & 302 & 2.910 & $\stackrel{\text { vv }}{=} \|_{\text {DLRV }}$ & weak & $\begin{array}{l}\text { Disturbed } \\
\text { laminar }\end{array}$ \\
\hline Fig 9d & M4 & 4.6 & backward & 314 & 2.910 & $\stackrel{\text { iv }}{\equiv} \| \mathrm{WSRV}_{\mathrm{WS}}$ & weak & $\begin{array}{l}\text { Disturbed } \\
\text { laminar }\end{array}$ \\
\hline
\end{tabular}




\begin{tabular}{|c|c|c|c|c|c|c|c|c|}
\hline & & & & Straig & d forw & ard blades & & \\
\hline Fig 10a B3 & 3.4 & straight & 213 & 2.078 & "'" & WSSA & $\begin{array}{l}\text { Rather } \\
\text { weak }\end{array}$ & Weak stall \\
\hline Fig 10b B3 & 3.8 & straight & 254 & 2.078 & $\stackrel{\text { '"' }}{\equiv}$ & WSTLWRV & $\begin{array}{l}\text { Rather } \\
\text { weak }\end{array}$ & Weak stall \\
\hline Fig 10c B3 & 4.1 & straight & 294 & 2.078 & "'"ß & HSTLWRV & $\begin{array}{l}\text { Rather } \\
\text { strong }\end{array}$ & Half stall \\
\hline Fig 10d B3 & 4.6 & straight & 360 & 2.078 & "'" & HSTLSRV & $\begin{array}{l}\text { Rather } \\
\text { strong }\end{array}$ & Half stall \\
\hline Fig 11a X3 & 3.4 & forward & 282 & 2.494 & $\stackrel{\mathrm{III}}{\Xi}$ & HSSATL & $\begin{array}{l}\text { Rather } \\
\text { strong }\end{array}$ & $\begin{array}{l}\text { Half stall } \\
\text { Tip Laminar }\end{array}$ \\
\hline Fig 11b X3 & 3.8 & forward & 338 & 2.494 & $\stackrel{\mathrm{III}}{\Xi}$ & HSSATL & $\begin{array}{l}\text { Rather } \\
\text { strong }\end{array}$ & $\begin{array}{l}\text { Half stall } \\
\text { Tip Laminar }\end{array}$ \\
\hline Fig 11c X3 & 4.1 & forward & 402 & 2.910 & $\equiv$ & HSSTLRV & $\begin{array}{l}\text { Rather } \\
\text { strong }\end{array}$ & $\begin{array}{l}\text { Half stall } \\
\text { Tip Laminar }\end{array}$ \\
\hline Fig 11d X3 & 4.6 & forward & 412 & 2.910 & 兲" & HSSTLRV & $\begin{array}{l}\text { Rather } \\
\text { strong }\end{array}$ & $\begin{array}{l}\text { Half stall } \\
\text { Tip Laminar }\end{array}$ \\
\hline Fig 12a M5 & 3.4 & forward & 294 & 2.494 & $\stackrel{\text { JpKo }}{\equiv}=$ & DHSRVTL & $\begin{array}{l}\text { Rather } \\
\text { strong }\end{array}$ & $\begin{array}{l}\text { Disturbed } \\
\text { Half stall }\end{array}$ \\
\hline Fig 12b M5 & 3.8 & forward & 326 & 2.494 & $\stackrel{\text { JpKod }}{\equiv}=$ & DHSRVTL & $\begin{array}{l}\text { Rather } \\
\text { strong }\end{array}$ & $\begin{array}{l}\text { Disturbed } \\
\text { Half stall }\end{array}$ \\
\hline Fig 12c M5 & 4.1 & forward & 364 & 2.910 & $\stackrel{\text { JpKod }}{\equiv}=$ & HSSRVTL & $\begin{array}{l}\text { Rather } \\
\text { strong }\end{array}$ & Half stall \\
\hline Fig 12d M5 & 4.6 & forward & 410 & 2.910 & $\stackrel{\mathrm{JpKo}}{\rightleftarrows}$ & HSSRVTL & $\begin{array}{l}\text { Rather } \\
\text { strong }\end{array}$ & Half stall \\
\hline
\end{tabular}

On Fig. 8, the tip flow of the backward blade X5 is strongly laminar. The stronger the wind velocity, the stall of the blade X5 moves slowly, as clearly seen, from a) laminar, b) disturbed laminar, c) weak stall and d) half stalls patterns. On this blade with regular hub and BERP III helicopter-like blade tip, there is no stall delay mechanism, as the wind velocity increases the disturbed and stall flow patterns from the blade root, slowly propagate toward the middle of the blade.

The tip flow of the backward blade M4 in Fig. 9 is also strongly laminar, due to the BERP IV helicopter-like blade tip. It is known that the backward blade slowdown the stall propagation from the root toward the middle of the blade. The slow down processes are amplified, as the finned hub of the blade generates strong rolled-up vortex disturbances onto the tufts of the blade main body. These truly interfere the growth of the blade stall, therefore the stall development is extensively weakened, and significantly delayed. Even though the wind speed already reaches 3.4 and $3.8 \mathrm{~m} / \mathrm{s}$ the blade root is still laminar, and at $4.6 \mathrm{~m} / \mathrm{s}$ the root still experiences weak stall.

Flow visualization for straight blade in Fig. 10 clearly shows strong laminar flows due to an additional blade tip. Increasing wind speed on the straight blade B3 of course generates a stronger strong stall growth. Once again, finned hub of the blade B3 generates strong rolled up vortex disturbance onto the tuft of the blade main body, disturbs the growth of the blade stall. Due to the stronger stall growth, the effect of finned hub of the blade could only produce a weak stall delay on the turbine blades.

In Fig. 11, the flow visualization for forward blade X3 with regular hub and BERP III helicopter-like blade tip shows the dramatic competition between a strong laminar flow at the blade tip against a strong stall growth in the main body due to the forward characteristic. The strong stall in the form of a half stall in the main body has happens since the beginning of the wind flow. The resulting flow is a strong laminar tip flow combined with half stall, strongly affected by the tip laminar flow, and with the weak rolled up vortex growing to strong rolled up 
vortex flows in the main body. Since there is no stall delay mechanism due to the absent of a fin in the hub, it develops situation as combination of a part with a half stall flow and the other part with the strong laminar flow.

The competition, for forward blade M5 with JpKd helicopter-like blade tip, between a strong stall growth in the main body due to the forward blade against i) the strong laminar flow at the blade tip and ii) the rolled up vortex due to the finned hub, shown clearly in the flow visualization, in Fig. 12. The main body stalls growth as a strong effect of the forward blade are delayed significantly by the strong rolled-up vortex effects. This phenomenon is clearly visible even when the wind velocity reaches high speed. It is clearly shown on Table 2 that maximum $\mathrm{Cp}$ reaches 0.027 at $\mathrm{v}=4.6 \mathrm{~m} / \mathrm{s}$.

The results of flow visualization, shown from Fig 8 to 12, could be summarized and presented on Table 3 showing the blade name, the type of the blade tip swept, the blade RPM, the tip speed ratio, Reynold number, stall propagation patterns due to the blade tip and finned hub, the degree of turbulence and stall types or flow characteristics. The abbreviations appear on the table have the following meanings. For backward blades X5 in Fig. 8, LWLD is laminar with little disturbance, DLSD is disturbed laminar with little stall disturbance, WSLD is weak stall with little disturbance and HSSS is half stall with strong stall disturbance. In Fig. 9 for the backward blade M4, in the blade with strong laminar region in the blade tip, a finned hub is introduced to delay stall growth on the blade main body. LSDR is laminar with some disturbed region, DLRV is disturbed laminar with rolled-up vortex effect and WSRV is weak stall with rolled-up vortex effect. The rolled-up vortex destroys or delays the stall growth.

In Fig. 10, the straight blade B3 is easier to stall then the backward one. WSSA is weak stall strongly accelerated. The finned hub that generates strong rolled up vortex disturbance could only produce weak stall delay. But the blade has laminar region in the blade tip. The finned hub and BERP III plays significant roles, therefore WSTLWRV is weak stall, tip laminar with weak rolled-up vortex effect. HSTLWRV is half stall, tip laminar, with weak rolled-up vortex effect; HSTLSRV is half stall, tip laminar with strong rolled-up vortex effect, showing weak stall delay.

Fig. 11 shows dramatic competition on the forward type of blade X3 with regular hub and BERP III blade tip. The blade begins with half stall. HSSATL is half stall, strongly affected by tip laminar flow, and HSSTLRV is half stall, strongly affected by tip laminar flow with rolled-up vortex. In Fig. 12, the competition on the forward type of blade M5 continues except that additional finned hub gives significant contributions to delay the stall to grow. DHSRVTL is disturbed half stall plus rolled-up vortex with tip laminar flow and HSSRVTL is half stall plus strong rolled-up vortex with tip laminar flow.

Learning that additional helicopter-like blade tips on the wind turbine blades could create strong laminar flows on the blade tips, it is strongly suspected that a helicopter blade tip is a combination of 2, 3 or 4 leading edge triangular corners on the precise synchronization and locations, each performs as a rolled-up vortex as in the finned hub. The synchronized location combination gives perfects strong laminar flows. "laminarized" the initially turbulent flow. This research would open opportunity to combine further finned hubs and helicopter-like blade tips on the wind turbine blades to increase performance further and possibly suppress the noise.

\subsection{The Results of the Performance Experiment versus the Mathematical Model}

From the wind tunnel measurements, presented in Table 1, 2, Fig. 6 and 7 show that it is still compelling for backward blades (BW) could give better performance than forward blades (FW). And from Table 1 and 2 one could find out that the backward blade X1 with regular hub and BERP IV blade tip reaches $\mathrm{Cp}=0.071$ at $\mathrm{v}=4.1$ $\mathrm{m} / \mathrm{s}$ and the backward blade M4 with finned hub and BERP IV helicopter-like blade tip reaches $\mathrm{Cp}=0.051$ at $\mathrm{v}$ $=4.1 \mathrm{~m} / \mathrm{s}$. Combination of a backward blades and BERP IV helicopter-like blade tips have been found to work at best.

It could be realized from blades with regular hub X1, X5 and X2 of Table 1 that the performance sequence for helicopter-like blade tip employment starts forms BERP IV, BERP III, and then JpKd. For blades with regular hub, as shown Table 1 and 2, the involvement of forward blade (FW) would present lower performance, since the stall growth would be accelerated by the bent of the blade in the same direction of the wind blows. The blades X3 and X4, with their poor performances, shows that SwTT gives poorer output than BERP III.

On Table 2, for blades with finned hub (HF), one could show that the finned hub generates rolled-up vortex disturbance onto the tuft of the blade main body. Comparing the blade X1 with M4, it shows that finned hub employment does not guarantee better results. The blade X1 performs better than M4. It is suspected that the finned hub "does not give influence" like the triangular fin sweep higher than 550 hence it does not create significant rolled-up vortex effects. 
For forward blade M5, it is thought that because of the rolled-up vortex of the finned hub, the forward blade M5 with finned hub gives better performance than forward blades X3 and X4 with regular hubs. It can also be concluded that the helicopter-like blade tip gives the following order of performance starts from the best: BERP IV, BERP III and JpKd or SwTT.

In the experiment results, exposed in Fig. 6 and 7, show the two blades X5 and M3 of wind turbine blades of the UGM 3-D type 2. These results show the power coefficient variation comparison with respect to the tip speed ratio between that based on a modified extended lifting-line theory employing 1/4-3/4 Pistolesi rule plus rotation with that measured actually in wind tunnel, it was found that they were in the correct trends.

One should notice also that the lifting line theory gives apparent discrepancy, maximum Cp goes to higher tip speed ratio when the wind speed becomes faster. On the other hand experimental results give lower maximum $\mathrm{Cp}$ when the wind blows slower. Therefore one could conclude that the mathematical model with the lifting line theory, still require improvements. For the time being, the lifting line mathematical models are only heavily dependent on the planform shape accuracy. Further improvement is under ongoing process.

\section{Conclusion}

Three-dimensional effects of additional finned hub and helicopter-like blade tip on forward or backward wind turbine blade configuration are studied in depth in this report.

From the combination of wind turbine blade plate-model performance, Table 1 and 2, and the flow visualization results from Fig. 8 to 12, it can be concluded that, it is still valid that the backward blades produce good performance, since stall propagation are weakened due to the stall growth propagation against the wind flow direction. The forward blade gives poor performance, since stall propagation are strengthened due to the stall growth propagation is aligned with the wind flow direction.

Employment of helicopter-like blade tips; BERP IV, BERP III, SwTT and JpKd, on the wind turbine blade tip plate-models create strong laminar flows over the surface of the blade tip. The backward blade models when combined with BERP IV blade tip, they give excellent performance. The BERP III blade tip gives better performance than SwTT blade tip. The performance sequence diminishes from BERP IV, BERP III toward SwTT or JpKd. Additional finned hub to the turbine blade creates rolled-up vortex weaken the stall growth development, even though slightly weaker, especially due to straight blades and forward blades at high-speed wind

Competition between strong laminar flows, over the surface of the blade tips, against stall propagation due to forward blades happens if there is no stall delay mechanism due to no fin in the hub. There is situation with combination of one part is a half stall flow and the other part is a strong laminar flow. Dramatic competition between strong laminar tip flows against stall due to forward blades, behaves differently if there is finned hub. The main body stall growth due to the forward blade was delayed significantly due to the strong rolled-up vortex effects.

$$
\begin{array}{lll}
\text { Nomenclature } & \\
\mathrm{b} & = & \text { half of rotor radius } \\
c_{a}, \mathrm{c}_{\mathrm{A}} & = & \text { lift coefficient } \\
\mathrm{c}_{\mathrm{d}} & =\text { drag coefficient } \\
\mathrm{d} & =\quad \text { rotor diameter } \\
\mathrm{V} & =\quad \text { the wind velocity }(\mathrm{m} / \mathrm{s}) \\
\mathrm{x} . \mathrm{y} & =\text { abscissa } \& \text { ordinate } \\
\mathrm{C}_{\mathrm{p}} & =\quad \text { coefficient of performance } \\
\mathrm{G}\left(\mathrm{x}_{\mathrm{P}}, \mathrm{y} ; \mathrm{y}^{\prime}\right) & =\text { influence function } \\
\mathrm{K}\left(\eta, \eta^{\prime}\right) & =\text { geometrical influence factor } \\
\mathrm{M} & =\quad \text { blade span section } \\
\mathrm{N} & =\text { blade number } \\
\mathrm{P}_{\mathrm{T}} & =\quad \text { output power of wind turbine }(\mathrm{W}) \\
\mathrm{P}_{\mathrm{W}} & =\quad \text { the wind power }(\mathrm{W}),
\end{array}
$$




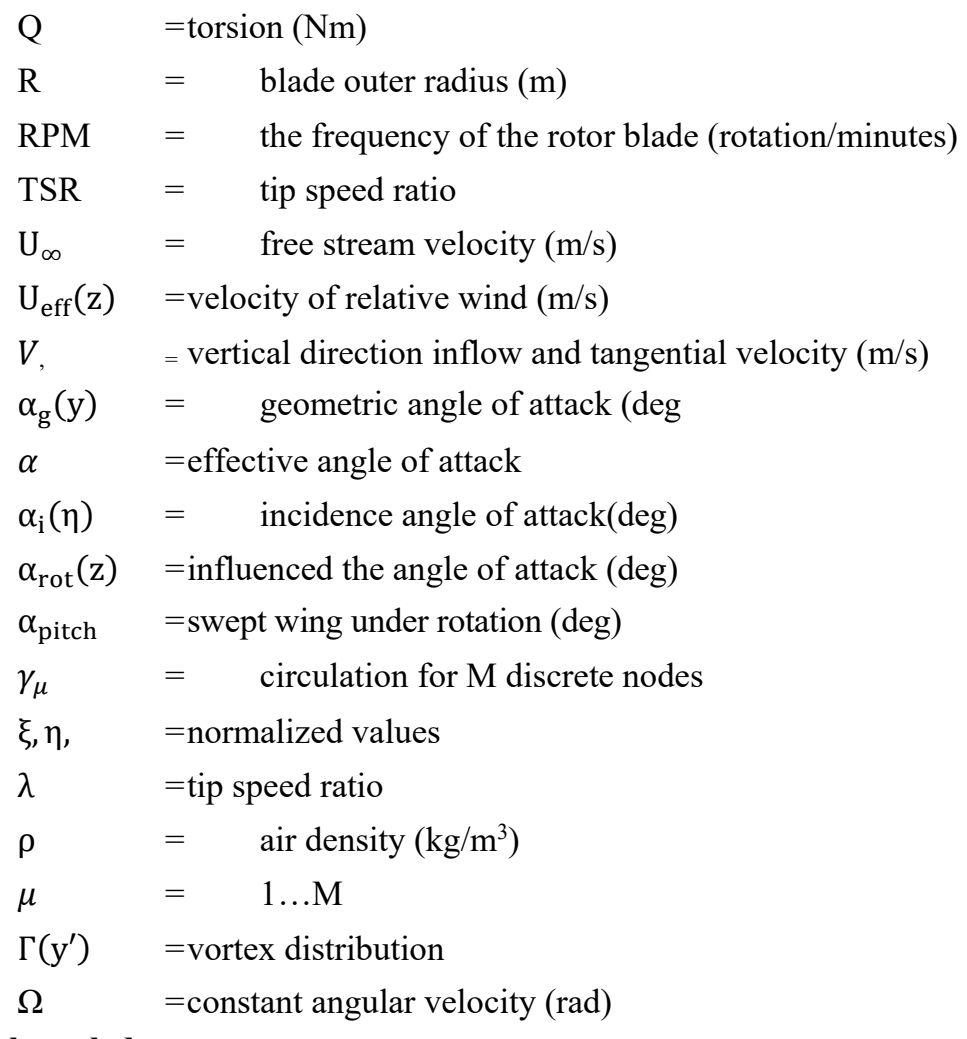

\section{Acknowledgments}

This work has been carried out with a support of the Department of Higher Education, Republic of Indonesia. The authors would like to express sincere gratitude to Dr. Purnomo, Dr. Muslim and Dr. Prajitno for time spent in serious discussion, helpful suggestion and useful conceptual contribution. We would like to thank also our students Widia, Dhanu, Surya, Hasan,Wega, Farhan, Yogi, my laboratory staffs Waji and Min, their helps in construction work and conducting data management are gratefully acknowledged.

\section{References}

Abdulhadi, F. (2012). Design and Characterization of a Small Wind Turbine Model equipped with a Pitching System Table of Contents.

Abedi, H. (2013). Development of Vortex Filament Method for Aerodynamic Loads on Rotor Blades.

Ayati, A. (2010). Aerodynamic Effects on Wind Turbine Blades Using the Lifting-Line Theory. University of Oslo.

Bak, C., Skrzypiński, W., Gaunaa, M., Villanueva, H., Brønnum, N. F., \& Kruse, E. K. (2016). Full scale wind turbine test of vortex generators mounted on the entire blade. Journal of Physics: Conference Series, 753, 22001. https://doi.org/10.1088/1742-6596/753/2/022001

Baldacchino, D., Manolesos, M., Ferreira, C., Gonzalez Salcedo, A., Aparicio, M., Chaviaropoulos, T., ... van Zuijlen, A. (2016). Experimental benchmark and code validation for airfoils equipped with passive vortex generators. Journal of Physics: Conference Series, 753(2), 1-13. https://doi.org/10.1088/1742-6596/753/2/022002

Bang, D., \& Polinder, H. (2007). New active speed stall control compared to pitch control for a direct-drive wind turbine.

Barlas, E., Zhu, W. J., Shen, W. Z., \& Andersen, S. J. (2016). Wind Turbine noise propagation modelling: an unsteady Approach. Journal of Physics: Conference Series, 753, 22003. https://doi.org/10.1088/1742-6596/753/2/022003

Bertagnolio, F. (2016). A noise generation and propagation model for large wind farms. In Proceeding 22nd International Congress on Acoustic (pp. 1-10).

Bertagnolio, F., Aagaard Madsen, H., Fischer, A., \& Bak, C. (2015). Basic principles and evidences of wind turbine noise generation mechanisms. 6th International Conference on Wind Turbine Noise. 
Boorsma, K., \& Schepers, J. G. (2011). Enhanced wind turbine noise prediction tool SILANT. Fourth International Meeting on Wind Turbine Noise, Rome, Italy, (FEBRUARY), 12-14.

Boorsma, K., \& Schepers, J. G. (2016). Rotor experiments in controlled conditions continued: New Mexico. Journal of Physics: Conference Series, 753, 22004. https://doi.org/10.1088/1742-6596/753/2/022004

Bourlis, D. (2011). A Complete Control Scheme for Variable Speed Stall Regulated Wind Turbines. In Dr. Rupp Carriveau (Ed.), Fundamental and Advanced Topics in Wind Power. InTech.

Brocklehurst, A., \& Barakos, G. N. (2013). A Review of Helicopter Rotor Blade Tip Shapes. Progress in Aerospace Sciences, 56, 35-74. https://doi.org/10.1016/j.paerosci.2012.06.003

de Oliveira, G., Pereira, R. B., Ragni, D., Avallone, F., \& van Bussel, G. (2016). How does the presence of a body affect the performance of an actuator disk? Journal of Physics: Conference Series, 753, 1-11. https://doi.org/10.1088/1742-6596/753/2/022005

Dumitrescu, H., \& Cardos, V. (2012). Inboard stall delay due to rotation. Journal of Aircraft, 49(1), 101-107. https://doi.org/10.2514/1.C031329

Dumitrescu, H., \& Cardoş, V. (1989). Inboard boundary layer state on wind turbine blades. ZAMM, 3, 163-173.

Dumitrescu, H., \& Cardoş, V. (2002). Delayed stall modelling of the rotating blades. In Proceedings of the Romanian Academy, Series A (Vol. 12, pp. 100-108).

Dumitrescu, H., Cardoş, V., \& Dumitrache, A. (2007). Modelling of inboard stall delay due to rotation. Journal of Physics: Conference Series, 75. https://doi.org/10.1088/1742-6596/75/1/012022

Elfarra, M. A. (2011). Horizontal Axis Wind Turbine Rotor Blade: Winglet and Twist Aerodynamic Design and Optimization Using CFD. Middle East Technical University.

Farouk, A., \& Gawad, A. (2013). New, simple blade-pitch control mechanism for small-size, horizontal-axis wind turbines. Journal of Energy and Power Engineering, 7, 2237-2248.

Ferreira, C., Gonzalez, A., Baldacchino, D., Aparicio, M., Gómez, S., Munduate, X., ... van Zuijlen, A. (2016). Results of the AVATAR project for the validation of 2D aerodynamic models with experimental data of the DU95W180 airfoil with unsteady flap. Journal of Physics: Conference Series, 753, 22006. https://doi.org/10.1088/1742-6596/753/2/022006

Gursul, I. Ã., Wang, Z., \& Vardaki, E. (2007). Review of flow control mechanisms of leading-edge vortices. Progress in Aerospace Sciences, 43, 246-270. https://doi.org/10.1016/j.paerosci.2007.08.001

Gursul, I., Gordnier, R., \& Visbal, M. (2005). Unsteady aerodynamics of nonslender delta wings. Progress in Aerospace Sciences, 41, 515-557. https://doi.org/10.1016/j.paerosci.2005.09.002

Hansen, C., Zajamsek, B., \& Hansen, K. (2015). Infrasound and low-frequency noise from wind turbines. https://doi.org/10.13140/RG.2.1.3826.5049

Hu, D., Hua, O., \& Du, Z. (2006). A study on stall-delay for horizontal axis wind turbine. Renewable Energy, 31(6), 821-836. https://doi.org/10.1016/j.renene.2005.05.002

Kuchemann, D. (1956). A Simple Method for Calculating the Span and Chordwise Loading on Straight and Swept Wings of any Given Aspect Ratio at Subsonic Speeds.

Lamar, J. (1968). A Modified Multhopp Approach for Predicting Lifting Pressures and Camber Shape for Composite Planforms in Subsonic Flow. Washington.

Lee, K., Huque, Z., Kommalapati, R., Roy, S., Sui, C., \& Munir, N. (2016). Aerodynamic noise characteristics of horizontal axis wind turbine blade using CAA. Journal of Clean Energy Technologies, 4(5), 346-352. https://doi.org/10.18178/JOCET.2016.4.5.310

Leroy, A., Braud, C., Baleriola, S., Loyer, S., Devinant, P., \& Aubrun, S. (2016). Comparison of flow modification induced by plasma and fluidic jet actuators dedicated to circulation control around wind turbine airfoils. Journal of Physics: Conference Series, 753, 22012. https://doi.org/10.1088/1742-6596/753/2/022012

Lutz, T. (2014). Flugzeugaerodynamik II (Aicraft aerodynamics II). Institut für Aerodynamik und Gasdynamik, Universität Stuttgart.

Lutz, T., \& Wagner, S. (2000). Numerical Shape Optimization of Subsonic Airfoil Sections. In European Congress on Computational Methods in Applied Sciences and Engineering ECCOMAS (pp. 1-20). 
Lynch, C. E. (2011). Advanced CFD Methods for Wind Turbine Analysis.

Maheswari, R. U., \& Tamilvendhan, J. (2012). Analysis of modelling of active stall controlled and active pitch controlled variable speed wind turbines. IJMER, 2(4), 2662-2667.

Maniaci, D. C., White, E. B., Wilcox, B., Langel, C. M., van Dam, C. P., \& Paquette, J. A. (2016). Experimental measurement and CFD model development of thick wind turbine airfoils with leading edge erosion. Journal of Physics: Conference Series, 753, 22013. https://doi.org/10.1088/1742-6596/753/2/022013

Martinez, J. (2007). Modelling and Control of Wind Turbines. Imperial College London London. https://doi.org/10.1007/978-3-642-41080

Mathew, J., Singh, A., Madsen, J., \& Arce León, C. (2016). Serration design methodology for wind turbine noise reduction. Journal of Physics: Conference Series, 22019. https://doi.org/10.1088/1742-6596/753/2/022019

Moller, H., \& Pedersen, C. S. (2010). Low-frequency noise from large wind turbines. The Journal of the Acoustical Society of America, 129(6), 3727. https://doi.org/10.1121/1.3543957

Möllerström, E., Ottermo, F., Hylander, J., \& Bernhoff, H. (2015). Noise emission of a $200 \mathrm{~kW}$ vertical axis wind turbine. Energies, 9, 1-10. https://doi.org/10.3390/en9010019

Muljadi, E., Pierce, K., \& Migliore, P. (1998). A concervative control strategy for variable-speed, stall-regulated wind turbines. In Proceedings of the American Society of Mechanical Engineers (ASME) Wind Energy Symposium (Vol. 3, pp. 1710-1714). https://doi.org/10.1109/ACC.1998.707298

Neammanee, B., Sirisumrannukul, S., \& Chatratana, S. (2010). Control strategies for variable-speed fixed-pitch wind turbines. In S. M. Muyeen (Ed.), Wind Power (pp. 209-230). Croatio: INTECH. https://doi.org/10.5772/8357

Okulov, V. L., Sørensen, J. N., \& Shen, W. Z. (2016). Extension of Goldstein's circulation function for optimal rotors with hub. Journal of Physics: Conference Series, 753, 22018. https://doi.org/10.1088/1742-6596/753/2/022018

Okulov, V. L., Sørensen, J. N., \& Wood, D. H. (2014). The rotor theories by Professor Joukowsky: Vortex theories. Progress in Aerospace Sciences, 1-28. https://doi.org/10.1016/j.paerosci.2014.10.002

Pereira, R., Bussel, G. J. W. Van, \& Timmer, W. a. (2014). Active stall control for large offshore horizontal axis wind turbines; A conceptual study considering different actuation methods. Journal of Physics: Conference Series, 555, 12082. https://doi.org/10.1088/1742-6596/555/1/012082

Perfilev, D. (2013). Methodology for Wind Turbine Blade Geometry Optimization. Lappeenranta University of Technology.

R. Kesler. (2014). Propeller Thrust Analysis Using Prandtl's Lifting Line Theory, A Comparison Between The Experimental Thrust And The Thrust Predicted By Prandtl's Lifting Line Theory. University of Utah.

Rahimi, H., Hartvelt, M., Peinke, J., \& Schepers, J. (2016). Investigation of the validity of BEM for simulation of wind turbines in complex load cases and comparison with experiment and CFD. Journal of Physics: Conference Series, 749, 12015. https://doi.org/10.1088/1742-6596/749/1/012015

Schepers, G. (2016). Latest results from the EU project AVATAR: Aerodynamic modelling of $10 \mathrm{MW}$ wind $\begin{array}{lllll}\text { turbines. Journal of Physics: Conference } & \text { Series, } 2017 .\end{array}$ https://doi.org/10.1088/1742-6596/753/2/022017

Schubel, P. J., \& Crossley, R. J. (2012). Wind turbine blade design. Energies, 5(9), 3425-3449. https://doi.org/10.3390/en5093425

Smith, M., Bullmore, A., Cand, M., \& Davis, R. (2012). Mechanisms of amplitude modulation in wind turbine noise. Acoustics 2012. Retrieved from https://hal.archives-ouvertes.fr/hal-00811262/

Søndergaard, B. (2014). Infrasound and low frequency noise from wind turbines, 1-12. Retrieved from http://iopscience.iop.org/1748-9326/6/3/035103/pdf/1748-9326_6_3_035103.pdf

Sørensen, J. N., Okulov, V. L., Mikkelsen, R. F., Naumov, I. V., \& Litvinov, I. V. (2016). Comparison of classical methods for blade design and the influence of tip correction on rotor performance. Journal of Physics: Conference Series, 753, 22020. https://doi.org/10.1088/1742-6596/753/2/022020

Strom, B., Brunton, S. L., \& Polagye, B. (2016). Intracycle angular velocity control of cross-flow turbines. Retrieved from http://arxiv.org/abs/1605.01671 
Sutrisno, Prajitno, Purnomo, \& Setyawan, B.W. (2016). The performance \& flow visualization studies of three dimensional (3-D) wind turbine blade models. Modern Applied Science, 10(5), $132-144$. https://doi.org/10.5539/mas.v10n5p132

Tahani, M., Rahbari, I., Memarian, S., \& Mirmahdian, S. (2011). Simulation and Technical Comparison of Different Wind Turbine Power Control Systems, 4233-4240. https://doi.org/10.3384/ecp110574233

Van Kuik, G. A. M. (2016). Momentum theory of Joukowsky actuator discs with swirl. Journal of Physics: Conference Series, 753, 22021. https://doi.org/10.1088/1742-6596/753/2/022021

Vanderkooy, J., \& Mann, R. (2014). Measuring wind turbine coherent infrasound. 6 Th International Conference on Wind Turbine Noise.

Vijae, R. (2011). Pitch Control of Horizontal Axis Wind Turbine. National Institute of Technology, Rourkela.

Wu, Y., Mun, H., \& Tang, H. (2015). A study of the energetic turbulence structures during stall delay. International Journal of Heat and Fluid Flow, 54, $183-195$. https://doi.org/10.1016/j.ijheatfluidflow.2015.05.013

Yu, G., Shen, X., Zhu, X., \& Du, Z. (2011). An insight into the separate fl ow and stall delay for HAWT. Renewable Energy, 36(1), 69-76. https://doi.org/10.1016/j.renene.2010.05.021

\section{Copyrights}

Copyright for this article is retained by the author(s), with first publication rights granted to the journal.

This is an open-access article distributed under the terms and conditions of the Creative Commons Attribution license (http://creativecommons.org/licenses/by/4.0/). 